\title{
PERKIRAAN UMUR KELELAHAN KONSTRUKSI LAMBUNG FSO DENGAN METODE SPECTRAL-BASED FATIGUE ANALYSIS
}

\author{
Sumardiono $^{1)}$, Eko B. Djatmiko ${ }^{2)}$, dan Handayanu ${ }^{2)}$ \\ ${ }^{1)}$ Mahasiswa Pasca Sarjana Program Studi Teknik Perancangan Bangunan Laut ITS \\ Surabaya \\ ${ }^{2)}$ Staf Pengajar Jurusan Teknik Kelautan ITS Surabaya \\ Kampus ITS - Sukolilo Surabaya 60111 \\ E-mail: die.kapalits@gmail.com
}

\begin{abstract}
This paper addresses the prediction of fatigue life for hull construction of Arco Ardjuna FSO operated in the West Java Sea. The method is based on the full spectral analysis and hot-spot stress approach. In the early stage, the study is conducted to analyze the wave loads using a hydrodynamic model to derive the global structural responses (vertical shear forces and vertical bending moments). These global responses are then set as the main input for the global structure analysis using a finite element model to obtain stress RAO for each critical location. Spectral Analysis is then performed to generate stochastic parameters that are used to identify the stress occurrence in the real ocean waves, which are random in nature. The short-term analysis (Rayleigh distribution) and long-term analysis (Weibull distribution) are further performed to obtain the stress distribution as well as the extreme stress range. Palmgren-Miner cumulative theory is next applied to calculate the fatigue damage directly correlated to the fatigue life. Closed-form fatigue equation, with the shape parameter of Weibull distribution, is then implemented to calculate the fatigue lifes at other critical locations in the FSO Structure.
\end{abstract}

Keywords: FSO, full spectral analysis, global structural responses, fatigue life

\begin{abstract}
ABSTRAK
Makalah ini menyampaikan studi mengenai perkiraan umur kelelahan dari konstruksi lambung FSO Arco Ardjuna yang beroperasi di perairan Laut Jawa Barat. Metode full spectral dan pendekatan tegangan hotspot diterapkan dalam studi ini. Sebagai tahapan awal, studi dilakukan melalui analisa beban gelombang dengan bantuan piranti lunak hidrodinamika, untuk memperoleh besaran respon struktur global (gaya geser vertikal dan momen lengkung vertikal). Respon struktur global ini merupakan input utama dalam analisa struktur global elemen hingga untuk memperoleh RAO tegangan setiap lokasi kritis. Analisa spektra kemudian dilakukan dan menghasilkan parameter-parameter stokastik yang digunakan untuk mengidentifikasi tegangan yang terjadi pada kondisi gelombang laut riil yang bersifat acak. Prosedur analisa kurun waktu pendek (distribusi Rayleigh) dan kurun waktu panjang (distribusi Weibull) dilakukan untuk mengetahui distribusi tegangan serta memperoleh rentang tegangan ekstrem terbesar selama masa operasional FSO. Teori komulatif Palmgren-Miner digunakan untuk menghitung indeks kelelahan yang berkorelasi langsung dengan umur kelelahannya. Persamaan kelelahan terangkai, dengan parameter bentuk dari distribusi Weibull, digunakan untuk memperkirakan umur kelelahan pada lokasi struktur kritis lainnya pada FSO. Dari hasil studi, diperoleh nilai tegangan ekstrem terbesar sebesar 62.29 MPa pada sambungan antara struktur memanjang LS-30 dan struktur melintang Frame No.20. Pada lokasi yang sama umur kelelahan minimal terjadi, yaitu sebesar 71.02 tahun.
\end{abstract}

Kata-kunci: FSO, Metode Full Spectral, Respon Struktur Global, Umur Kelelahan

\section{PENDAhULUAN}

Dalam proses perancangan dan operasional bangunan laut, isu keselamatan (safety issue) merupakan tolok ukur kualitas bangunan laut, terutama dalam aspek desain strukturnya. Kerusakan struktur bangunan laut pada umumnya diakibatkan oleh kelelahan (fatigue), baik itu pada komponen struktur utama maupun struktur sekunder dan tersier. Biaya perawatan dan reparasi bangunan laut dialokasikan dengan proporsi yang lebih besar untuk mengatasi kerusakan tersebut [1]. Penyebab utama bangunan laut mengalami kelelahan adalah karena beban 
lingkungan, terutama beban gelombang yang bersifat siklis (cyclic) dan berulang (repetition). Oleh karena itu, analisa mengenai kemampuan struktur yang mengalami beban kelelahan sangat diperlukan untuk menjamin bahwa stuktur mampu bertahan selama masa operasionalnya.

Kajian dan penelitian mengenai analisa kelelahan dalam memperkirakan umur kelelahan pada konstruksi lambung FSO telah banyak dilakukan. Diantara metode yang digunakan adalah Deterministic Fatigue Analysis dan Simplified Fatigue Analysis. Namun mengingat karakteristik gelombang yang bersifat acak, maka Spectral-based Fatigue Analysis dianggap lebih bisa mengakomodir kondisi riil di perairan [2]. Studi mengenai kelelahan struktur berbasis spektral sebelumnya telah dilakukan oleh beberapa peneliti terhadap beberapa obyek struktur bangunan laut, diantaranya pada kapal tanker [2, 3], VLCC dan FPSO [4], kapal Roro [5], dan kapal trimaran [6]. Pada penelitian kali ini membahas obyek struktur FSO sebagai salah satu bangunan laut terapung yang digunakan sebagai fasilitas utama dalam industri minyak lepas pantai, yaitu sebagai fasilitas penampungan minyak hasil eksploitasi.

Dalam metode-metode perhitungan umur kelelahan struktur, pendekatan yang digunakan dalam penentuan besarnya tegangan menjadi salah satu tahapan penting, salah satunya adalah pendekatan tegangan hotspot. Pendekatan ini memberikan kelebihan dibandingkan dengan pendekatan tegangan nominal, terutama dikarenakan oleh kemampuannya dalam menentukan besarnya tegangan pada jenis dan variasi detail sambungan struktur. Tingkat akurasi yang lebih tinggi karena pengukuran tegangan hotspot yang terjadi pada sambungan las sudah memperhitungkan pengaruh dari geometri struktur.

Secara umum, makalah ini akan menyajikan informasi mengenai prosedur perhitungan respon tegangan dalam bentuk Response Amplitude Operator (RAO) pada lokasi kritis konstruksi lambung FSO sebagai akibat dari beban gelombang quasi-statis. FSO yang dijadikan obyek kajian adalah FSO Arco Ardjuna milik PHE ONWJ yang dioperasikan di Laut Jawa Barat. Analisa struktur dilakukan dengan menggunakan Finite Element (FE) Method melalui tahapan meshing global (ukuran elemen mesh relatif besar) dan meshing lokal (ukuran elemen mesh yang lebih kecil). Output dari analisa struktur, yang berupa RAO Tegangan, merupakan input utama dalam melakukan analisa spektral untuk memperoleh parameter-parameter stokastik yang digunakan sebagai dasar perhitungan jumlah kejadian tegangan hostspot pada kondisi perairan riil. Analisa kurun waktu pendek dan kurun waktu panjang kemudian dilakukan untuk mengetahui distribusi tegangan hotspot yang terjadi, sekaligus tegangan ekstremnya. Sebagai tahapan akhir dari analisa ini yaitu perhitungan indeks kelelahan dengan mengadopsi teori komulatif Palmgren-Miner. Berbagai ketentuan dalam prosedur analisa dilakukan dengan mengikuti aturan-aturan yang tercantum dalam klas [7, 8], diantaranya adalah terkait proses pemodelan struktur, variasi kondisi pembebanan dan sambungan kritis yang harus ditinjau.

\section{TINJAUAN PUSTAKA}

\subsection{Data dan Identifikasi Obyek}

FSO Arco Ardjuna (FSO AA) dibangun di Mitsubishi Heavy Industries, Nagasaki, Jepang pada tahun 1972. Secara keseluruhan FSO ini mterdiri dari 9 (sembilan) tangki muatan minyak, ruang pompa, tanpa tangki ballast, tanpa sistem penggerak dan tidak memiliki sistem pencucian minyak sendiri. Ruang-ruang akomodasi digabungkan menjadi satu lokasi dengan dek helikopter berada di atasnya. Bersama dengan Kamar mesin, ruang akomodasi ini berada tepat di atas tangki bagian depan. Mengenai tempat operasinya, FSO ini dioperasikan di perairan Laut Jawa Barat. Data parameter utama FSO Arco Ardjuna yang akan dijadikan obyek dalam studi ini disajikan pada Tabel 1.

Data berupa spesifikasi teknis dan gambar-gambar perencanaan FSO Arco Ardjuna digunakan untuk keperluan pemodelan hidrodinamis dan struktur elemen hingga. Gambar General Arrangement memberikan informasi mengenai konfigurasi tangki-tangki muatan, ruangruang akomodasi dan tata letak peralatan lainnya. Sedangkan Midship Section digunakan sebagai salah satu dasar dalam pemodelan dan analisa struktur elemen hingga. 
Tabel 1 Parameter utama FSO Arco Ardjuna

\begin{tabular}{|llll|}
\hline Loa & $:$ & 142.6 & meters \\
\hline $\mathrm{B}$ & $:$ & 48.2 & meters \\
\hline $\mathrm{H}$ & $:$ & 26.5 & meters \\
\hline $\mathrm{T}_{\text {full load }}$ & $:$ & 24 & meters \\
\hline Number of Tanks & $:$ & 9 & tanks \\
\hline Tank Capacity & $:$ & $1,022,000$ & barrels \\
\hline Function & $:$ & Storage and Offloading System \\
\hline
\end{tabular}

Data lingkungan yang diperlukan berupa data sebaran gelombang (wave scatter diagram) Laut Jawa Barat, yang menyajikan informasi mengenai jumlah kejadian satu-tahunan untuk setiap variasi tinggi gelombang dan periode gelombang (Tabel 2). Data ini selanjutnya digunakan dalam perhitungan spektrum energi gelombang, dimana jumlah total variasinya adalah 14 (empat belas) nilai periode gelombang (Tp) dan 8 (delapan) nilai tinggi gelombang signifikan (Hs).

Tabel 2 Data sebaran gelombang Laut Jawa Barat

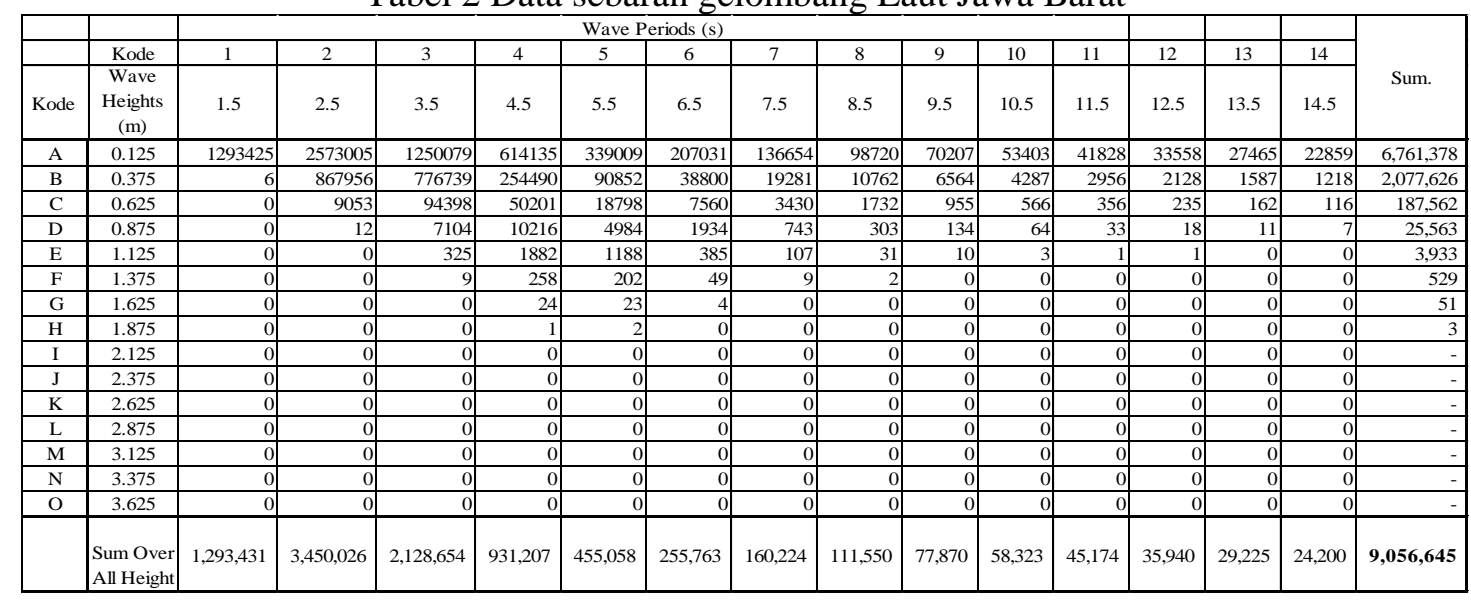

Untuk tujuan kemudahan dalam mengidentifikasi variasi kombinasi antara tinggi dan periode gelombang pada data sebaran gelombang Laut Jawa Barat, penulis menggunakan kode penamaan sea state yang selanjutnya disebut dengan "Mode Operasi". Untuk variasi tinggi gelombang, digunakan kode penamaan sesuai dengan urutan huruf abjad (huruf "A" digunakan untuk tinggi gelombang 0,125 meter, sampai dengan huruf " $H$ " untuk tinggi gelombang 1,875 meter). Sedangkan periode gelombang diidentifikasikan dengan kode penamaan sesuai urutan angka (angka " 1 " berarti periode gelombang 1,5 detik, sampai dengan angka " 14 " untuk periode gelombang 14,5 detik).

Analisa karakteristik beban dan tegangan kurun waktu panjang serta perhitungan umur kelelahan struktur dilakukan dengan batasan kondisi sebagai berikut:

- FSO kondisi muatan penuh (full load), dengan sarat air 24 meter.

- Beban gelombang divariasikan berdasarkan arah dan tinggi gelombang. Arah datang gelombang terdiri dari 3 (tiga) macam, yaitu head sea, beam sea dan following sea. Sedangkan tinggi gelombang sejumlah 8 (delapan) variasi.

Kombinasi dari beberapa variasi variabel ini akan menghasilkan kombinasi kasus pembebanan yang disebut load case. Rentang frekuensi yang digunakan adalah $0.25 \mathrm{rad} / \mathrm{s}$ sampai $1.65 \mathrm{rad} / \mathrm{s}$ dengan interval $0.1 \mathrm{rad} / \mathrm{s}$. 
Perhitungan rentang tegangan (stress range) dilakukan pada setiap lokasi sambungan kritis, yaitu Frame 9 sampai Frame 11, Frame 14 sampai Frame 16 dan Frame 19 sampai Frame 21 pada setiap kasus pembebanan (load case). Detail sambungan struktur pada masing-masing lokasi tersebut ditampilkan dalam bentuk sketsa pada Gb. 1.

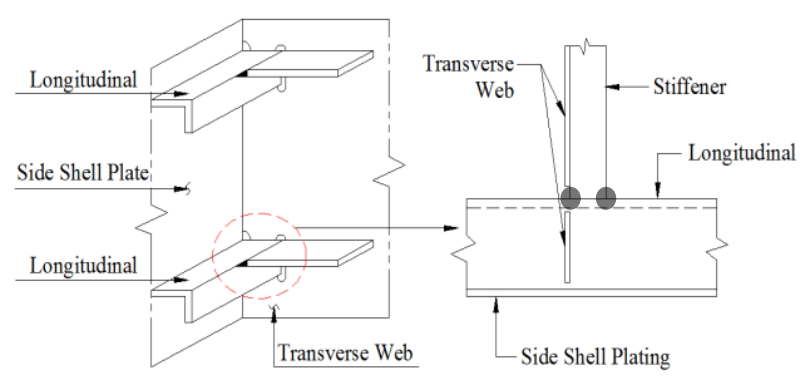

Gambar 1 Sketsa sambungan pada lokasi kritis

\subsection{Dasar Teori}

Respon gerakan akibat eksitasi gelombang reguler memberikan efek primer pengaruh dinamis terhadap respons struktur global. Komponen respon struktur terbagi menjadi 2 (dua) kelompok, yaitu komponen vektor gaya geser (V) dan komponen vektor momen (M) sesuai dengan sistem sumbunya. Komponen vektor gaya geser pada setiap potongan melintang terdiri dari gaya kompresi $\left(V_{l}\right)$, gaya geser horisontal $\left(V_{2}\right)$ dan gaya geser vertikal $\left(V_{3}\right)$. Sedangkan untuk momen dengan mengacu pada sumbu-sumbu yang sama terdiri dari momen torsi $\left(M_{4}\right)$, momen lengkung vertikal $\left(M_{5}\right)$ dan momen lengkung horisontal $\left(M_{6}\right)$ [9]. Hasil komputasi dari respons struktur global akibat eksitasi beban gelombang reguler ini disajikan dalam bentuk kurva Response Amplitude Operator (RAO) sebagai fungsi dari frekuensi gelombang. Presentasi semacam ini disebut dengan RAO gaya geser dan RAO momen yang diperlukan terutama dalam analisa spektra untuk memperoleh indikasi respon struktur di atas gelombang acak. RAO ini dihitung pada semua variasi rentang frekuensi gelombang dan arah datang gelombang yang dipertimbangkan dalam analisa.

Gaya geser dan momen sebagai respon struktur karena pengaruh beban gelombang ini diaplikasikan secara langsung pada struktur bangunan laut melalui analisa elemen hingga untuk memperoleh tegangan struktur dalam bentuk RAO tegangan (Stress RAO). Dalam analisa struktur ini, dimungkinkan adanya penerapan geometri pemodelan secara parsial dari obyek struktur global. Dalam hal ini penentuan nilai gaya geser dan momen lengkung harus dilakukan dengan teliti dan tepat dalam merepresentasikan kondisi batas di masing ujung dari geometri model yang dipertimbangkan.

Analisa kelelahan berbasis spektral dimulai setelah perhitungan RAO tegangan, disebut juga fungsi transfer tegangan. Secara matematis persamaan spektral respon tegangan diformulasikan dalam bentuk berikut :

$S_{\sigma}\left(\omega \mid H_{s}, T_{z}, \theta\right)=\left|R A O_{\sigma}(\omega \mid \theta)\right|^{2} . S_{\eta}\left(\omega \mid H_{s}, T_{z}\right)$

dimana:

$S_{\sigma} \quad: \quad$ Spektrum respons tegangan struktur $\left(\mathrm{m}^{2}-\mathrm{sec}\right)$

$S_{\eta} \quad:$ Spektrum gelombang $\left(\mathrm{m}^{2}-\mathrm{sec}\right)$

$R A O$ : Fungsi transfer tegangan

$\omega \quad$ : Frekuensi gelombang $(\mathrm{rad} / \mathrm{sec})$

$H_{S} \quad$ : Tinggi gelombang signifikan (m)

$T_{z} \quad$ : Periode gelombang (sec)

$\theta \quad: \quad$ Arah (sudut datang) gelombang relatif terhadap arah haluan (m)

Spektrum energi gelombang $\left(S_{\eta}\right)$ yang digunakan adalah JONSWAP sesuai data sebaran gelombang dan variasi frekuensi gelombang dengan parameter puncak $(\gamma)=2.5$. 
Kerusakan kelelahan (fatigue damage) dari masing-masing sea state dihitung menggunakan fungsi kepadatan peluang Rayleigh dimana fungsi ini menggambarkan distribusi rentang tegangan dalam kurun waktu pendek, momen spektral berbagai tingkatan orde, kurva S$\mathrm{N}$ sesuai dengan detail struktur dan frekuensi (jumlah kejadian) rentang tegangan yang terjadi. Berdasarkan teori akumulasi kerusakan Palmgren-Miner, dengan peluang terjadinya kondisi operasional dan lingkungan yang berbeda, maka jumlah kumulatif dari fatigue damage ditentukan dengan menggabungkan kerusakan kurun waktu pendek untuk semua variasi sea state yang dipertimbangkan [6]. Dengan mempertimbangkan semua peluang kejadian sebagai faktor dari skenario operasi, maka fungsi kepadatan peluang dari respon gerakan moda tertentu dalam kurun waktu panjang, atau satu periode operasi, misalnya satu tahun, dapat dituliskan sebagai:

$$
p_{L}\left(\zeta_{r}\right)=\frac{\sum_{a} \sum_{b} \sum_{c} n x p_{a} p_{b} p_{c} x p_{s}\left(\zeta_{r}\right)}{\sum_{a} \sum_{b} \sum_{c} n x p_{a} p_{b} p_{c}}
$$

dengan:

$n \quad=$ jumlah siklus per satuan waktu

$p_{a} \quad=$ peluang kejadian gabungan tinggi dan periode gelombang

$p b \quad=$ peluang kejadian arah gelombang

$p c \quad=$ peluang kejadian atau pembobotan faktor kondisi pembebanan operasional

$p s\left(\zeta_{R}\right)=$ fungsi kepadatan peluang kejadian respons dalam kurun waktu pendek.

Dengan mengasumsikan bahwa respon tegangan kurun waktu pendek yang terjadi merupakan narrow-banded, maka penentuan rentang tegangan adalah mengikuti distribusi peluang Rayleigh. Maka kemudian dengan menggunakan momen spektral pada beberapa tingkatan orde, fungsi kepadatan peluang Rayleigh dapat menggambarkan distribusi rentang tegangan kurun waktu pendek dan jumlah kejadian dari tegangan, yang dihitung dengan persamaan sebagai berikut:

$g(\sigma)=\frac{\sigma}{4 m_{0}} \exp \left(-\frac{\sigma^{2}}{8 m_{0}}\right)$

$f=\frac{1}{2 \pi} \sqrt{\frac{m_{2}}{m_{0}}}$

dimana:

$g(\sigma) \quad$ : Fungsi kepadatan peluang Rayleigh

$f \quad:$ Jumlah kejadian per detik

$\sigma \quad$ : Rentang tegangan

$m_{0}, m_{2} \quad$ : Momen spektral

Jumlah keseluruhan respons yang diharapkan akan terjadi selama periode operasi dalam kurun waktu panjang kemudian dapat diperoleh dari:

$n_{L}=\left(\sum_{a} \sum_{b} \sum_{c} n_{0} x P_{a} P_{b} P_{c}\right) \times T$

$T$ adalah waktu keseluruhan operasi dalam satuan detik. Variabel $n$ akan terdistribusi mulai dari harga amplitudo respon yang terkecil sampai dengan terbesar yang mungkin terjadi, mengikuti bentuk distribusi Weibull :

$F(\Delta \sigma)=1-Q(\Delta \sigma)=1-\exp \left[-\left(\frac{\Delta \sigma}{q}\right)^{\xi}\right]$

dimana $Q$ adalah peluang terjadinya rentang tegangan $\Delta \sigma$, $\xi$ adalah parameter bentuk Weibull dan $q$ adalah parameter skala Weibull. Parameter bentuk $\xi$ ini tergantung dari jenis bangunan laut, lokasi detail struktur yang ditinjau, dan perairan tempat beroperasi selama masa operasional. Nilai parameter skala $q$ dapat diperoleh dari parameter bentuk dan rentang tegangan awal $\Delta \sigma_{0}$, yang terjadi sekali dalam jumlah siklus $\mathrm{n}_{0}$, didefinisikan dalam tingkat probabilitas $\mathrm{n}_{0}{ }^{-1}$ sebagai berikut:

$q=\frac{\Delta \sigma_{0}}{\left(\ln \left(n_{0}\right)\right)^{1 / \xi}}$ 
Analisa mengenai kerusakan struktur akibat kelelahan yang disebabkan oleh beban yang bersifat acak adalah didasarkan pada konsep kegagalan komulatif. Asumsi dasar dari pendekataan ini adalah bahwa kerusakan struktur pada satu siklus beban bersifat konstan pada rentang tegangan tertentu [6].

Perhitungan indeks kelelahan (D) dilakukan dengan penerapan teori komulatif PalmgrenMiner dan dapat dituliskan dengan formulasi matematis :

$$
D=\frac{N_{L}}{A} \frac{S_{e}^{m}}{\left(\ln N_{R}\right)^{m} / \xi} \Gamma(1+m / \xi)
$$

Dalam persamaan di atas terdapat parameter distribusi Weibull sebagai fungsi kepadatan peluang untuk rentang tegangan, dengan variabel sebagai berikut:

$N_{L} \quad$ : Jumlah keseluruhan siklus kejadian selama masa operasional

$A, m$ : Parameter kurva S-N

$S_{e} \quad$ : Rentang tegangan ekstrem $\left[\mathrm{N} / \mathrm{mm}^{2}\right]$

$\xi \quad$ : Parameter bentuk Weibull

Tegangan hotspot merupakan tegangan lokal yang terjadi di daerah sekitar lokasi indikasi keretakan. Besarnya nilai tegangan hotspot dapat ditentukan dengan cara ekstrapolasi linier terhadap akar las yaitu dengan menggunakan nilai tegangan pada jarak 0,5t dan 1,5t sebagai referensi, dimana t di sini adalah ketebalan pelat dalam satuan milimeter. Metode lainnya dalam penentuan tegangan hotspot ini adalah dengan menggunakan faktor pengali sebesar 1,12 terhadap besarnya tegangan yang dihasilkan pada jarak 0,5t dari akar las [10]. Metode yang terakhir ini, dikenal juga dengan metode satu titik, memberikan nilai tegangan hotspot yang lebih tinggi dibandingkan dengan metode ekdtrapolasi linier. Sehingga dengan demikian, umur kelelahan yang dihasilkan pun memberikan faktor keamanan yang tinggi juga. Rentang tegangan hotspot $(\Delta \sigma)$ didefinisikan sebagai:

$$
\Delta \sigma=2 \sigma_{a}
$$

dimana $\sigma_{\mathrm{a}}$ adalah amplitudo tegangan hotspot.

\section{METODOLOGI}

Secara umum, metodologi Spectral-based Fatigue Analysis disajikan secara skematis seperti terlihat pada Gb. 3. Prosedur yang tercantum ini menggunakan data gelombang dalam bentuk diagram sebaran gelombang yang merepresentasikan karakteristik gelombang satutahunan di perairan Laut Jawa Barat.

Sebagai tahapan awal adalah melakukan analisa hidrodinamis untuk mengetahui respon dinamis akibat gelombang reguler terhadap struktur global FSO, direpresentasikan dalam RAO beban gelombang. RAO ini kemudian digunakan sebagai input utama dalam analisa struktur model 3-dimensi elemen hingga. Analisa kurun waktu pendek ini selanjutnya menjadi dasar dalam konsep akumulasi untuk memperoleh karakteristik beban gelombang acak dalam kurun waktu panjang.

Analisa struktur dilakukan untuk setiap kombinasi dari variasi frekuensi dan arah datang gelombang. Analisa ini menhasilkan nilai tegangan sebagai output, dimana tegangan ini selanjutnya digunakan untuk membentuk sebuah fungsi transfer tegangan yang disebut RAO tegangan pada setiap lokasi struktur kritis sesuai dengan yang telah didefinisikan. Bersama-sama dengan spektrum gelombang, RAO tegangan merupakan input dari perhitungan spektrum respon tegangan berdasarkan Pers. (3). 


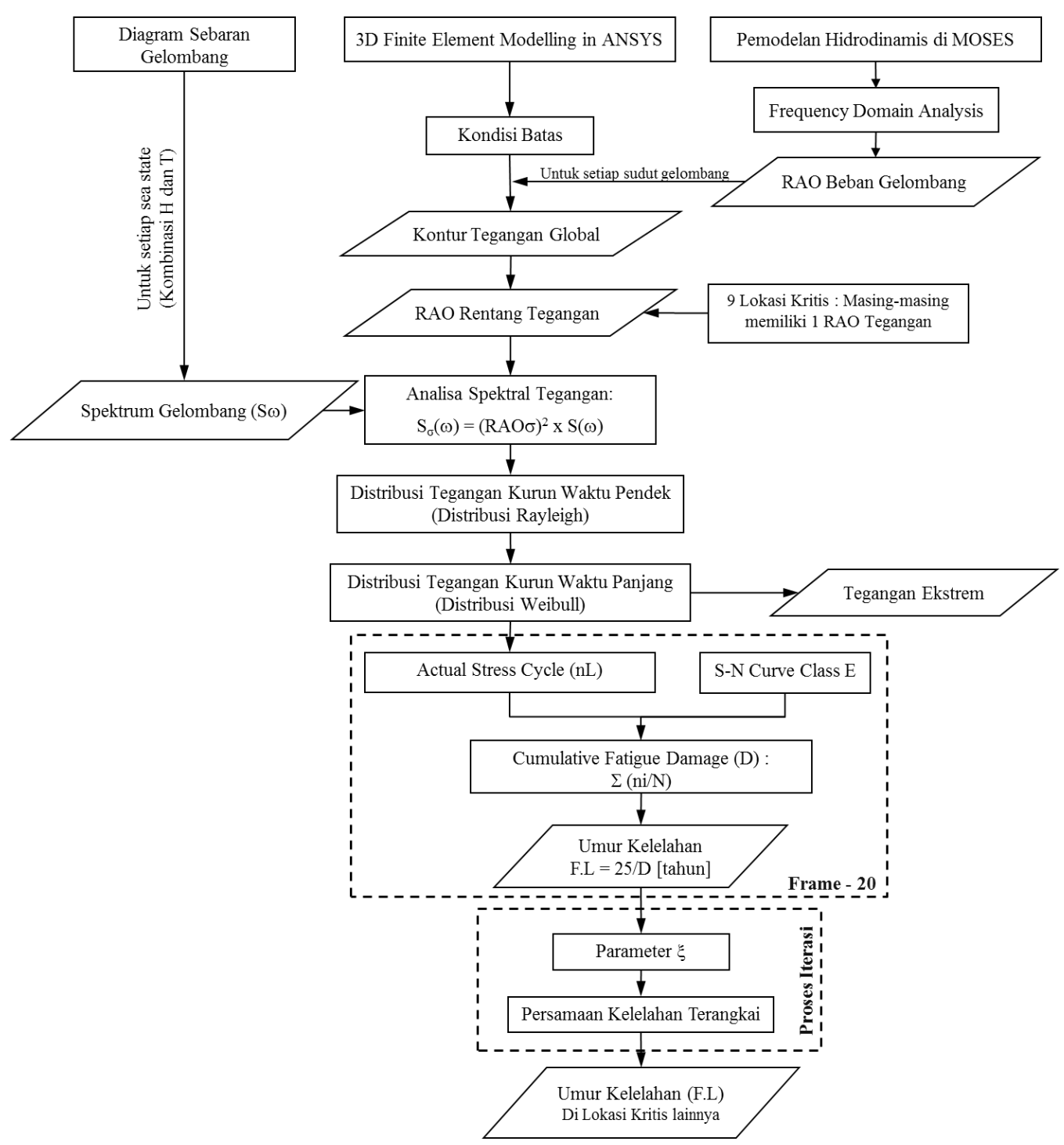

Gambar 3 Metodologi Spectral-based Fatigue Analysis

Dalam pembahasan mengenai analisa kurun waktu pendek, rentang tegangan diperoleh dari fungsi kepadatan peluang untuk setiap variasi yang sudah ditentukan, yaitu berdasarkan data yang tercantum dalam diagram sebaran gelombang. Fungsi kepadatan peluang dalam analisa kurun waktu pendek ini diperoleh melalui metode spektral berdasarkan pendekatan distribusi Rayleigh, dimana nilai-nilai tegangan yang terjadi diasumsikan narrow banded sesuai dengan proses acak Gaussian [11].

Distribusi rentang tegangan kurun waktu panjang diperoleh dengan mempertimbangkan peluang kejadian dari semua variasi sea state dan sudut datang gelombang dan digambarkan mengikuti Distribusi Weibull.

Perhitungan umur kelelahan dilakukan untuk tiap-tiap kasus pembebanan pada 9 (sembilan) lokasi sambungan kritis. Umur kelelahan dihitung berdasarkan pendekatan kurva S-N dengan menerapkan teori linier kerusakan komulatif Palmgren-Miner. Jumlah total dari perhitungan Fatigue Damage $\left(D_{i}\right)$ dari masing-masing sambungan tersebut menghasilkan indeks kelelahan komulatif (Cumulative Fatigue Damage (DM)). Indeks ini selanjutnya dijadikan input untuk menghitung umur kelelahan struktur (Fatigue Life) berdasarkan Pers. (12) dengan mengasumsikan umur perancangan struktur 25 tahun.

Umur Kelelahan $=\frac{\text { Umur Perancangan }}{D M} \quad[$ tahun $]$ 


\section{HASIL DAN PEMBAHASAN}

\subsection{Analisa Hidrodinamis}

Pemodelan hidrodinamis dilakukan dengan bantuan piranti lunak Bentley MOSES, mencakup bentuk lambung FSO, kompartemen-kompartemen serta definisi posisi dari setiap peralatan dan perlengkapan yang berada di atas geladak sebagai komponen dari berat kosong (light weight) FSO.

Respon struktur global dianggap sebagai efek primer dari gerakan di atas gelombang sehingga merupakan bagian terpenting dari keseluruhan proses perancangan bangunan laut [8]. Respon struktur akibat eksitasi gelombang reguler disebut dengan RAO beban gelombang (wave load $R A O$ ). Dalam studi ini respon struktur global yang dipertimbangkan dalam analisa adalah berupa gaya geser vertikal dan momen lengkung vertikal. Hasil komputasi untuk masing-masing respon disajikan pada Gb. 4 dengan mempertimbangkan FSO dalam kondisi stasioner.

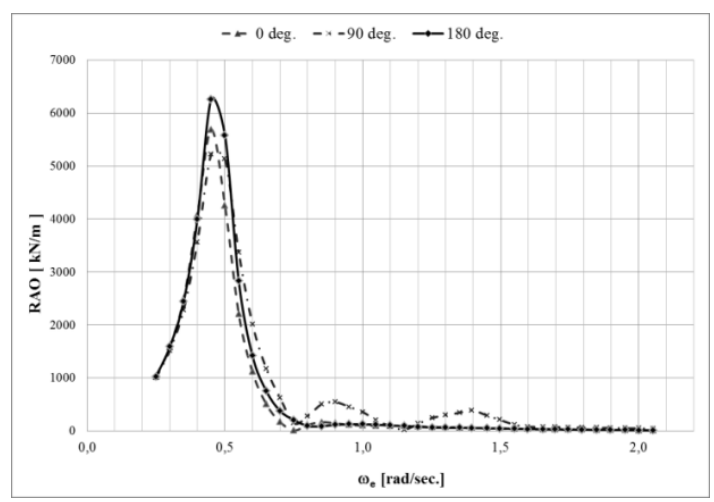

(a)

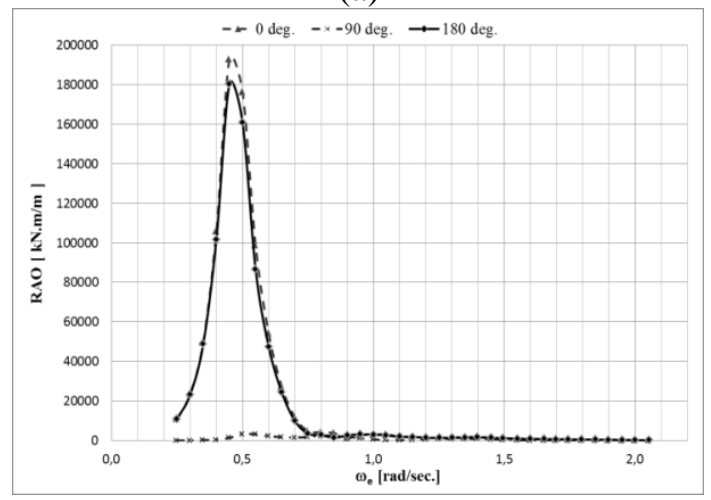

(b)

Gambar 4 RAO beban gelombang (a) Gaya geser vertikal dan (b) Momen lengkung vertikal

\subsection{Analisa Tegangan Struktur}

Geometri model dibuat dengan 3D Global Finite Element Modeling dengan bantuan piranti lunak ANSYS 16.0 Version dan mendasarkan pada ketentuan-ketentuan klas [3]. Struktur global FSO yang dibuat dalam pemodelan disajikan pada Gb.5, yaitu dimulai dari Frame 5 sampai dengan Frame 25. Penentuan cakupan lokasi ini sudah memenuhi definisi dari daerah amidship dari FSO. 


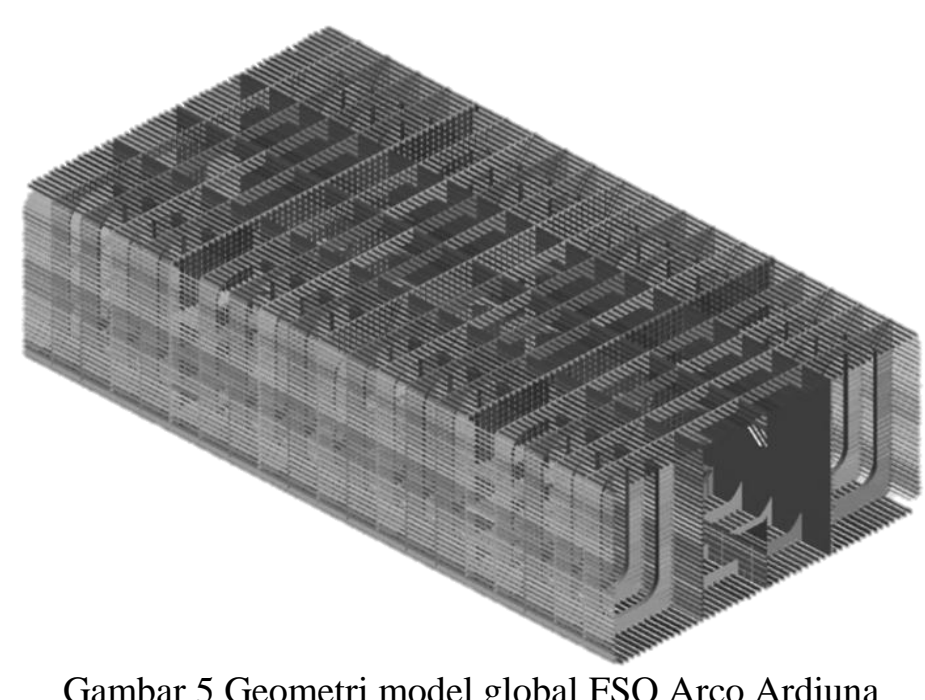

Dalam struktur global FSO, pemodelan konstruksi terdiri atas pelat dek, pelat dasar, pelat lambung, konstruksi penguatan memanjang (2 (dua) sekat memanjang dan 1 (satu) center girder) dan konstruksi penguatan melintang (ordinary frame, web frame, swash bulkhead dan oil tight bulkhead). Jarak antar konstruksi melintang adalah 4.6 meter sedangkan sekat memanjang masing-masing 9.9 meter dai center line.

Penggunaan tipe elemen shell dan elemen beam mempertimbangkan kompleksitas struktur secara keseluruhan. Elemen shell digunakan pada member struktur utama, seperti pelat lambung, pelat frame, pelat sekat memanjang dan pelat center girder. Sedangkan untuk konstruksi penguat (stiffener) digunakan elemen beam.

Ketentuan ukuran elemen meshing untuk struktur pelat atau shell mengikuti konfigurasi sistem penguatan atau penegar pada geometri global. Sebagai misal pada konstruksi melintang web frame, setidaknya terdapat satu elemen meshing pada satu jarak pembujur (longitudinal stiffener) dan tidak melebihi sampai dua kali jarak tersebut (Gb. 6a). Tahapan meshing yang seperti ini sering disebut dengan istilah Global Coarse Meshing.

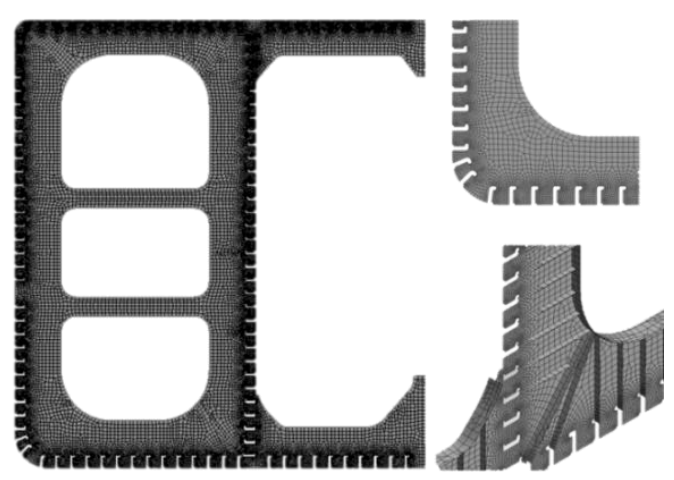

(a) 


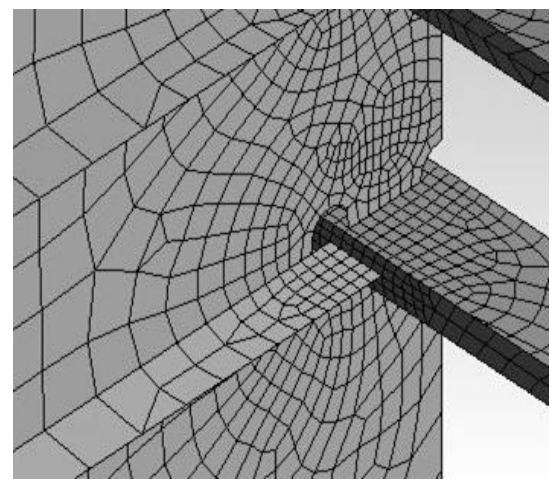

(b)

Gambar 6 Proses meshing pada Web Frame (a) Global Coarse Meshing dan (b) Local Fine Meshing

Untuk daerah yang kritis sesuai dengan tinjauan lokasi yang diperkirakan terjadi konsentrasi tegangan tinggi (hotspot), maka diperlukan ukuran elemen meshing yang lebih kecil. Proses meshing lokal yang seperti ini disebut dengan Local Fine Meshing (Gb. 6b). Ukuran meshing berdasarkan klas [7] untuk geometri lokal atau lokasi kritis adalah sebesar t x t, dimana $\mathrm{t}$ adalah ketebalan pelat, sehingga ukuran elemen meshing yang digunakan dalam analisa ini adalah $10 \mathrm{~mm} \times 10 \mathrm{~mm}$. Untuk geometri dengan tipe elemen shell atau pelat, elemen meshing berupa elemen segi empat (quadrilateral). Jumlah total elemen mesh adalah 856.131 elemen dengan 852.020 jumlah node, seperti tampak screenshot yang disajikan pada Gb.7.

\begin{tabular}{|c|c|c|c|}
\hline \multicolumn{3}{|c|}{ Details of "Mesh" } & प7 \\
\hline \multicolumn{4}{|c|}{ + Display } \\
\hline$\oplus$ & \multicolumn{3}{|l|}{ Defaults } \\
\hline$\Phi$ & \multicolumn{3}{|l|}{ Sizing } \\
\hline$\oplus$ & \multicolumn{3}{|l|}{ Inflation } \\
\hline+ & \multicolumn{3}{|c|}{ Patch Conforming Options } \\
\hline$\oplus$ & \multicolumn{3}{|c|}{ Patch Independent Options } \\
\hline$\oplus$ & \multicolumn{3}{|l|}{ Advanced } \\
\hline+ & \multicolumn{3}{|l|}{ Defeaturing } \\
\hline \multicolumn{4}{|c|}{ Statistics } \\
\hline & Nodes & 852020 & \\
\hline & $\square$ Elements & 856131 & \\
\hline & Mesh Metric & None & \\
\hline
\end{tabular}

Gambar 7 Jumlah total node dan elemen mesh

Untuk setiap analisa yang dilakukan, komponen-komponen beban yang diaplikasikan meliputi beban berat struktur sendiri, tekanan hidrostatik eksternal dari air laut, tekanan hidrostatik internal dari muatan minyak, gaya geser vertikal dan momen lengkung vertikal. Sedangkan mengenai kondisi batas yang diterapkan adalah seperti tercantum pada Tabel 3. Hal ini merujuk pada ketentuan yang sudah ditetapkan dalam klas [3].

Tabel 3 Kondisi Batas

\begin{tabular}{|c|c|c|c|c|c|c|}
\hline \multirow{2}{*}{ Location } & \multicolumn{3}{|c|}{ Translation } & \multicolumn{3}{|c|}{ Rotation } \\
\hline & $\delta_{\mathrm{x}}$ & бy & $\delta z$ & $\theta_{\mathrm{x}}$ & $\theta y$ & $\theta z$ \\
\hline \multicolumn{7}{|c|}{ Aft. End } \\
\hline Aft end (all longitudinal elements) & RL & - & - & - & - & RL \\
\hline Independent Point aft. End & Fix & $F_{y}$ & - & - & - & $M_{v-\text { end }}$ \\
\hline Side Shell and Longitudinal Bulkheads & - & - & Springs & - & - & - \\
\hline \multicolumn{7}{|c|}{ Fore End } \\
\hline Fore end (all longitudinal elements) & RL & - & - & - & - & RL \\
\hline Independent Point Fore End & Fix & $F_{y}$ & - & - & - & $M_{v \text {-end }}$ \\
\hline Side Shell and Longitudinal Bulkheads & - & - & Springs & - & - & - \\
\hline
\end{tabular}


Mengingat analisa ini adalah berbasis frequency domain analysis, maka komponen beban gaya geser vertikal dan momen lengkung vertikal memiliki besaran yang berbeda untuk setiap frekuensi dan variasi sudut datang gelombang, seperti yang telah dijelaskan sebelumnya (Gb. 4). Hasil tegangan yang terjadi akibat aplikasi komponen beban-beban tersebut di atas adalah berupa maximum principal stres. Output berupa distribusi tegangan yang terjadi pada struktur global FSO secara tipikal ditampilkan pada Gb. 8. Proses yang sama dilakukan untuk 45 (empat puluh lima) loadcase. Selanjutnya, seperti yang ditampilkan pada Gb. 9, dilakukan pengukuran tegangan pada setiap lokasi tinjauan sesuai dengan Tabel 3.

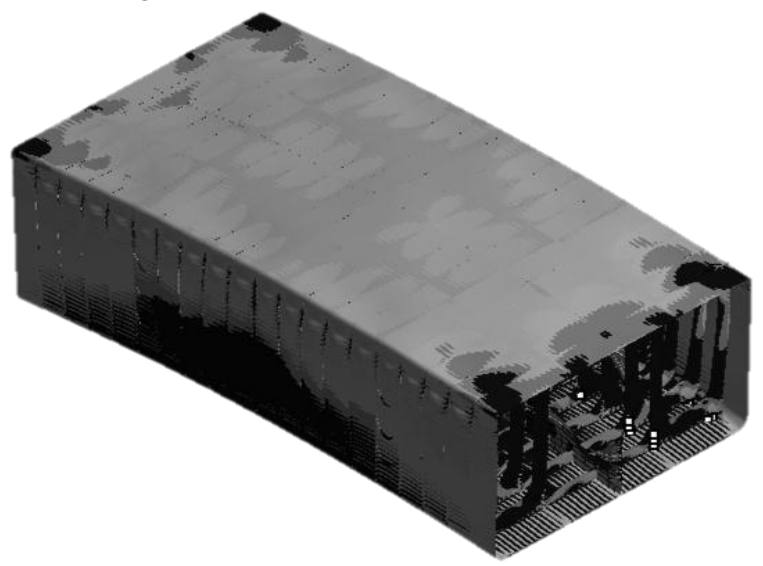

(a)

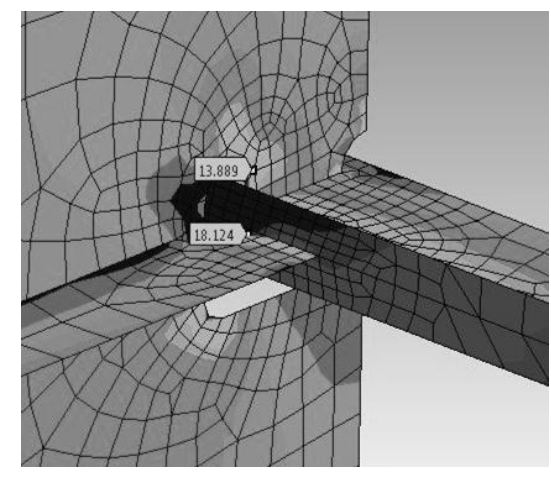

(b)

Gambar 8 Distribusi tegangan: (a) struktur global dan (b) struktur lokal

\subsection{Analisa Spektra Tegangan}

Dalam analisa spektra tegangan, RAO tegangan merupakan fungsi transfer untuk mengetahui respon struktur dari pendekatan gelombang reguler ke pendekatan gelombang acak sebagai representasi kondisi perairan yang riil. Besaran tegangan dihitung pada setiap variasi frekuensi encounter gelombang dengan menjadikan gaya geser vertikal dan momen lengkung memanjang sebagai input utama beban struktur akibat gelombang. Output dari analisa tegangan pada setiap lokasi kritis disajikan pada Gb. 9 yang menunjukkan RAO rentang tegangan pada 3 (tiga) variasi arah datang gelombang. Tegangan yang dihasilkan ini merupakan jenis tegangan hotspot dan rentang tegangan hotspot diperoleh dari Pers. (11). 


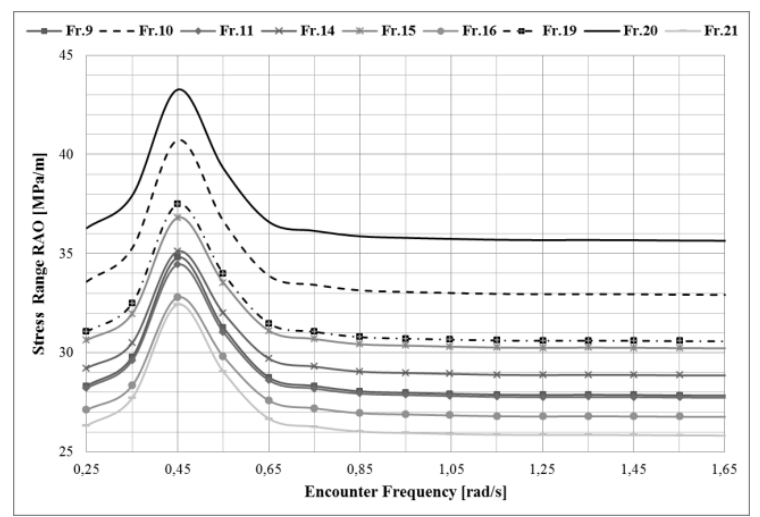

(a)

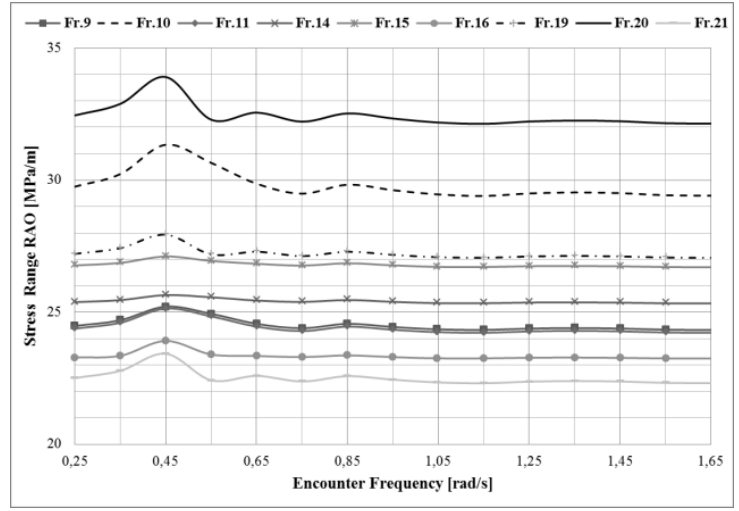

(b)

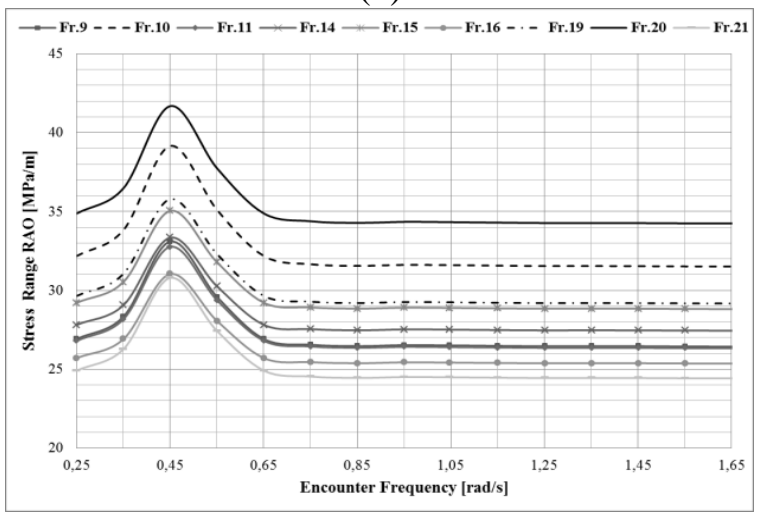

(c)

Gambar 9 RAO tegangan: (a) Head Sea; (b) Beam Sea dan (b) Following Sea

Kecenderungan pola dari kurva RAO tegangan yang diperoleh (Gb. 10) menunjukkan bahwa pada tinjauan lokasi kritis yang sama, besarnya RAO tegangan paling tinggi terjadi pada saat arah gelombang head sea kemudian diikuti dengan following sea dan paling rendah terjadi pada arah gelombang beam sea. Pola yang identik, penulis temukan pada penelitian yang telah dilakukan sebelumnya, seperti disajikan pada Gb. 10 untuk RAO tegangan yang terjadi pada kapal tanker dengan tinjauan lokasi kritis di deck longitudinal pada kondisi muatan penuh [2]. 


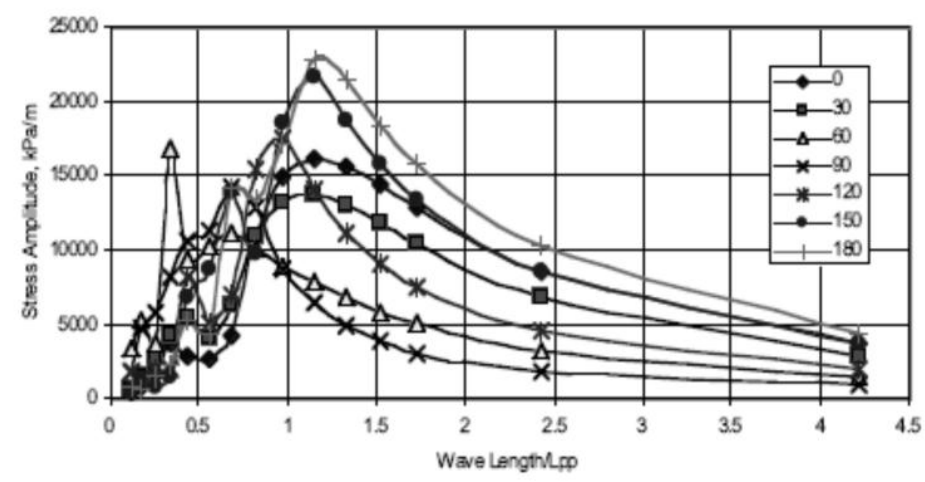

Gambar 10 RAO tegangan pada deck longitudinal - kondisi muatan penuh kapal tanker [2]

Informasi lain yang dapat diperoleh adalah bahwa pada setiap variasi arah datang gelombang, RAO tegangan yang terbesar terjadi di lokasi Frame 20. Berturut-turut kemudian diikuti dengan lokasi pada Frame 10 dan selanjutnya Frame 15. Atas dasar pertimbangan itu maka penulis memfokuskan obyek analisa kelelahan pada lokasi Frame 20 terlebih dahulu, yang selanjutnya merupakan dasar untuk analisa untuk lokasi kritis yang lain.

Analisa Spektra Gelombang dihitung pada seluruh sea state, dengan mengaplikasikan formulasi spektra JONSWAP, dan untuk setiap frekuensi gelombang. Perhitungan spektrum respon tegangan dilakukan berdasarkan Pers. (3) pada lokasi sambungan kritis Frame 20 untuk semua mode operasi dan semua variasi arah gelombang, sehingga diperoleh kurva spektrum respon tegangan seperti ditampilkan pada Gb. 11 .

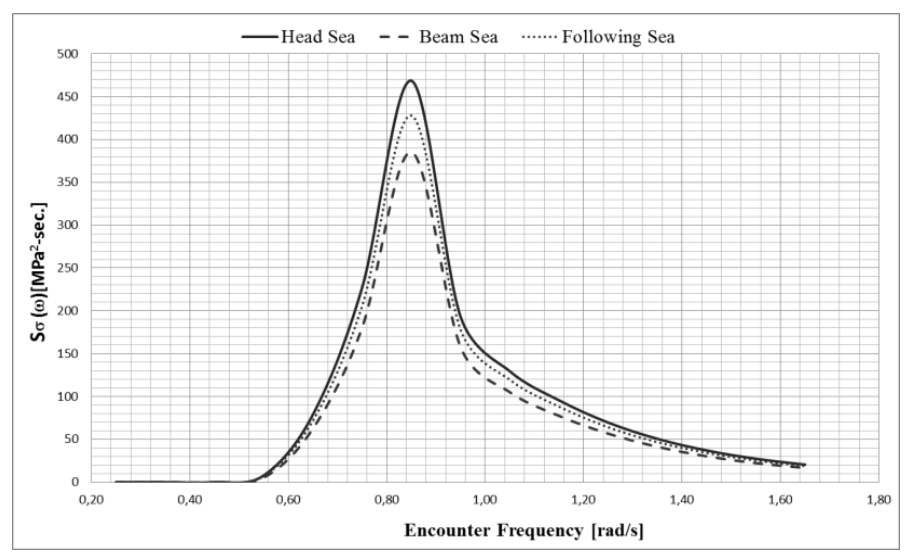

Gambar 11 Spektrum respon tegangan mode F-7

Tabel 4 Angka stokastik analisa rentang tegangan kurun waktu pendek - mode F-7

\begin{tabular}{|l|r|r|r|}
\hline \multirow{2}{*}{ Notasi } & \multicolumn{3}{|c|}{ Heading Angle } \\
\cline { 2 - 4 } & \multicolumn{1}{|c|}{ Head Sea } & \multicolumn{1}{c|}{ Beam Sea } & Following Sea \\
\hline $\mathbf{m}_{\mathbf{0}}$ & 133.18893 & 107.82209 & 121.96020 \\
\hline $\mathbf{m}_{\mathbf{2}}$ & 127.14047 & 103.25429 & 116.74243 \\
\hline $\mathbf{S}_{\mathbf{e x t}}$ & 44.48 & 40.02 & 42.56 \\
\hline $\mathbf{P}_{\mathbf{0}}$ & 0.333333 & 0.33333 & 0.333333 \\
\hline $\mathbf{n}$ & 0.16 & 0.16 & 0.16 \\
\hline $\mathbf{n}_{\mathbf{2 5} \text { tahun }}$ & $122,595,516$ & $122,791,110$ & $122,764,289$ \\
\hline $\mathbf{n}_{(\mathbf{H s}, \mathbf{T}}$ & 9 & 9 & 9 \\
\hline $\mathbf{n}_{(\mathbf{H s}, \mathbf{T} 25 \text { tahun }}$ & 10,233 & 10,250 & 10,247 \\
\hline
\end{tabular}

Hasil perhitungan harga-harga stokastik untuk analisa kurun waktu pendek yang mengikuti bentuk Distribusi Rayleigh seperti yang tercantum pada Tabel 5. Variabel-variabel dalam kolom "Notasi" pada Tabel 8 dijelaskan sebagai berikut:

$\mathrm{m}_{0} \quad$ : Luasan di bawah kurva spektra 
$\mathrm{m}_{2} \quad$ : Momen kedua dari luasan di bawah kurva spektra

$\mathrm{S}_{\mathrm{ext}} \quad$ : Tegangan ekstrim (MPa)

$\mathrm{P}_{\theta} \quad$ : Peluang kejadian berdasarkan arah datang gelombang

n : Jumlah kejadian per detik; Distribusi Rayleigh (cycle/detik)

$\mathrm{n}_{25}$ tahun : Jumlah kejadian selama 25 tahun (cycle)

$\mathrm{n}_{(\mathrm{Hs}, \mathrm{T})} \quad$ : Jumlah kejadian pada Hs dan $\mathrm{T}$ tertentu; diambil dari data gelombang (cycle)

$\mathrm{n}_{\text {(Hs, } \mathrm{T} 25 \text { tahun) }}$ Jumlah total kejadian pada Hs dan T tertentu selama 25 tahun (cycle)

\subsection{Analisa Kelelahan}

Perhitungan umur kelelahan FSO Arco Ardjuna dengan menggunakan metode spektral ini dilakukan melalui prosedur analisa kurun waktu panjang (long-term analysis) yang pada dasarnya merupakan akumulasi dari analisa spektra kurun waktu pendek. Histogram yang dihasilkan dari perhitungan membentuk kurva yang mengikuti distribusi Rayleigh, seperti ditunjukkan pada Gb. 12 untuk mode operasi F-7. Dalam studi ini, perhitungan umur kelelahan tidak memperhitungkan koreksi rainflow.

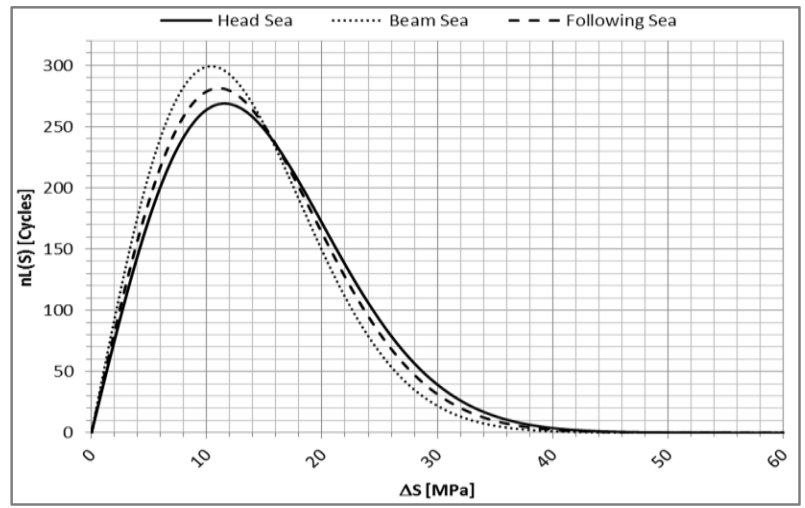

Gambar 12 Distribusi rentang tegangan kurun waktu pendek untuk mode F-7

Hal lain yang dapat diidentifikasi dari hasil analisa spektra kurun waktu panjang adalah intensitas respons ekstrem, yang berdasarkan pada peluang terjadinya yaitu sekali selama umur operasi, dalam hal ini dipertimbangkan 25 tahun. Gb. 13 menyajikan hasil plotting dalam bentuk log-log yang menyajikan hubungan antara jumlah kejadian dan respon berupa rentang tegangan. Diperoleh informasi bahwa rentang tegangan ekstrem yang berpeluang terjadi hanya sekali dalam umur operasi adalah $65,29 \mathrm{MPa}$.

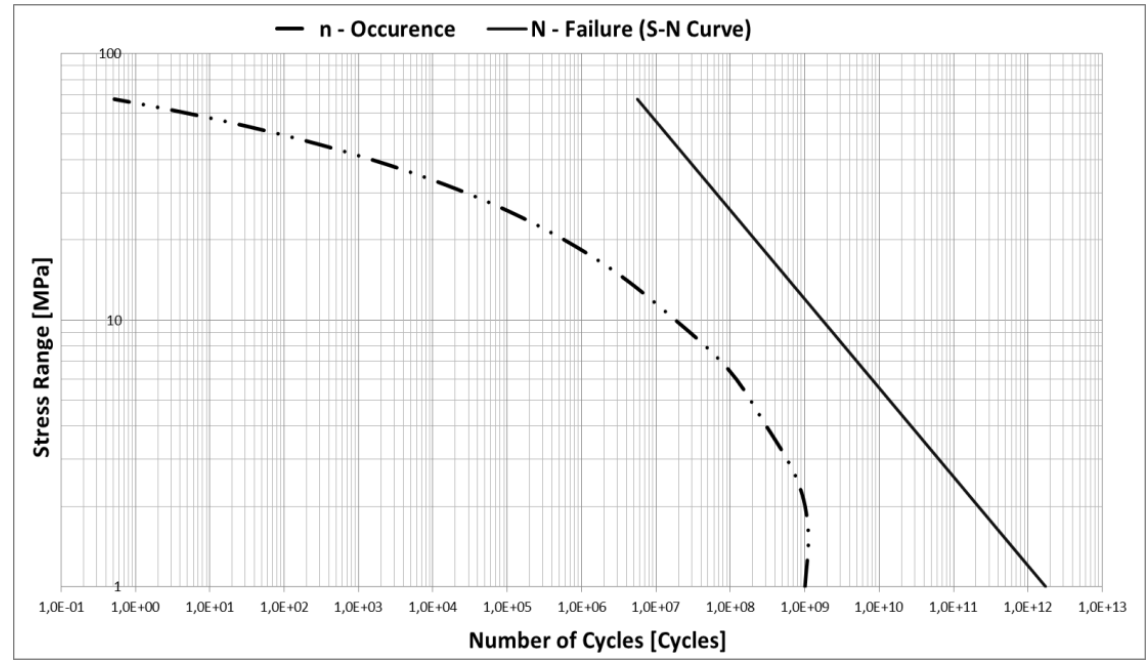

Gambar 13 Distribusi tegangan kurun waktu panjang 
Besarnya siklus tegangan untuk selama waktu operasi $\left(\mathrm{n}_{\mathrm{L}}\right)$ selanjutnya dibandingkan dengan jumlah siklus tegangan dimana sebuah struktur mengalami kegagalan $(\mathrm{N})$. Kurva S-N yang digunakan dalam analisa kelelahan dengan pendekatan tegangan hotspot setara dengan Class $E$ dengan parameter A dan m secara berturut-turut sebesar 3.28776E+12 dan 3. Dari perhitungan ini dihasilkan indeks kelelahan (D) yang merupakan akumulasi dari masing-masing $n_{L} / N$, diperoleh D untuk sambungan antara LS-30 dan sekat melintang frame 20 adalah sebesar 0,352. Selanjutnya perbandingan antara desain umur operasional FSO, yaitu 25 tahun, dengan indeks ini menghasilkan umur kelelahan (fatigue life) sebesar 71,02 tahun.

Persamaan kelelahan terangkai dalam memperkirakan umur kelelahan pada lokasi kritis lain.. Dalam persamaan tersebut terdapat parameter $\xi$ yang merupakan parameter bentuk dari distribusi weibull. Parameter ini dapat diperoleh dari proses iterasi sebagai bagian dari teknik optimasi. Penulis menggunakan bantuan fitur solver pada microsoft excel dalam melakukan proses ini. Dari hasil perhitungan dihasilkan besaran parameter $\xi$ sebesar 1,316 . Tabel 5 merupakan rekapitulasi dari proses perhitungan indeks kelelahan pada setiap sambungan antara LS-30 dan konstruksi melintang sesuai dengan obyek tinjauan.

Tabel 5 Rekapitulasi indeks dan umur kelelahan

\begin{tabular}{|c|c|c|c|c|}
\hline Lokasi & $\begin{array}{c}\text { Rentang Teg. Ekstrem }\left(\mathbf{S}_{\mathbf{e}}\right) \\
{[\mathbf{M P a}]}\end{array}$ & $\begin{array}{c}\text { Rasio Kelelahan } \\
(\mathbf{D})\end{array}$ & $\begin{array}{c}\text { Design Life } \\
{[\text { Years ] }}\end{array}$ & $\begin{array}{c}\text { Fatigue Life } \\
{[\text { Years ] }}\end{array}$ \\
\hline Fr.9 & 45,84 & 0,12 & 25 & 205,28 \\
\hline Fr.10 & 54,19 & 0,20 & 25 & 124,25 \\
\hline Fr.11 & 45,66 & 0,12 & 25 & 207,72 \\
\hline Fr.14 & 47,48 & 0,14 & 25 & 184,67 \\
\hline Fr.15 & 49,74 & 0,16 & 25 & 160,63 \\
\hline Fr.16 & 44,05 & 0,11 & 25 & 231,26 \\
\hline Fr. 19 & 50,33 & 0,16 & 25 & 155,09 \\
\hline Fr. 20 & 65,29 & 0,35 & 25 & 71,02 \\
\hline Fr. 21 & 42,52 & 0,10 & 25 & 257,18 \\
\hline
\end{tabular}

Umur kelelahan terkecil terjadi pada sambungan di Frame 20 dimana di daerah ini mengalami tegangan ekstrem yang paling besar dibanding lokasi lain. Hubungan linier antara besar rentang tegangan ekstrem dengan umur kelelahan struktur disajikan pada Gb. 14 .

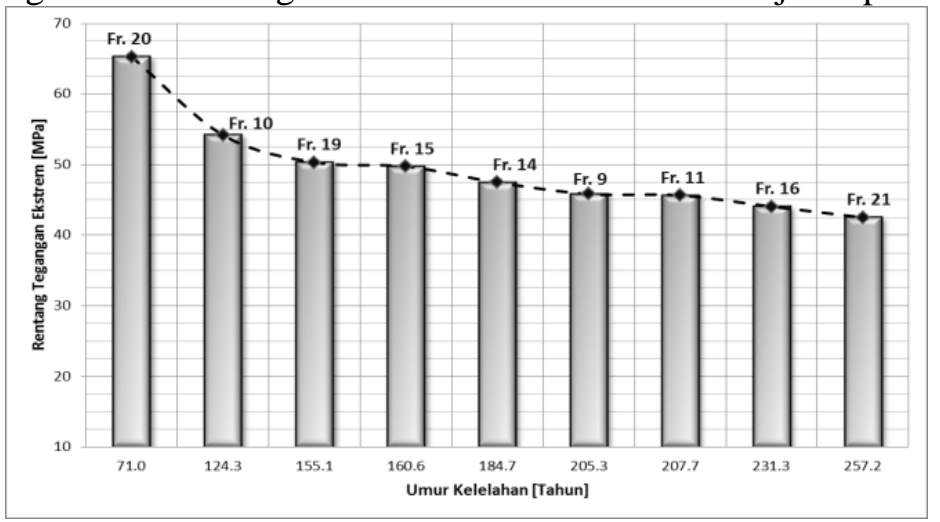

Gambar 14 Hubungan rentang tegangan ekstrem dan umur kelelahan

Dari keseluruhan konstruksi global FSO AA, 2 (dua) lokasi kritis yang memiliki umur kelelahan terkecil berada pada Frame 20 dan Frame 10. Dua lokasi ini merupakan konstruksi melintang sekat kedap (oil tight bulkhead) yang mana merupakan batas antar tangki muatan. Mengingat beban yang diaplikasikan pada struktur juga memperhitungkan beban internal dari muatan minyak, maka khusus pada dua lokasi ini mengalami beban dari dua arah/sisi. Biro Klasifikasi Indonesia (BKI) telah melakukan analisa kelelahan pada tahun 2012 dengan simplified method dan pendekatan nominal stress pada konstruksi FSO AA [12]. Sebagai hasil dari analisanya umur kelelahan kritis berada pada daerah LS-28 sampai LS-30 terutama pada sambungan dengan struktur melintang lokasi Frame Frame 10 dan Frame 20. Kesimpulan yang 
dihasilkan sekaligus sebagai hasil rekomendasinya adalah menambahkan konstruksi backing bracket untuk posisi LS-28 sampai LS-30.

\section{KESIMPULAN}

Analisa dan pembahasan mengenai studi perkiraan umur kelelahan konstruksi FSO Arco Ardjuna menghasilkan kesimpulan sebagai berikut:

1. Distribusi tegangan kurun waktu panjang direpresentasikan oleh kurva hubungan antara rentang tegangan dengan jumlah siklus kejadiannya. Rentang tegangan ekstrem yang terjadi pada struktur kritis FSO Arco Ardjuna Lokasi-1 sampai dengan struktur kritis Lokasi-9 secara berturut-turut adalah sebesar 45,84 MPa, 54,19 MPa, 45,66 MPa, 47,48 MPa, 49,74 MPa, 44,05 MPa, 50,33 MPa, 62.29 MPa dan 42,52 MPa.

2. Umur kelelahan pada struktur kritis FSO Arco Ardjuna kode Lokasi-1 sampai dengan struktur kritis kode Lokasi-9 secara berturut-turut adalah sebesar 205,28 tahun, 124,25 tahun, 207,72 tahun, 184,67 tahun, 160,63 tahun, 231,26 tahun, 155,09 tahun, 71,02 tahun dan 257,18 tahun. Hal ini memberikan informasi bahwa semua lokasi tinjauan sambungan kritis memiliki umur kelelahan melebihi umur perancangan 25 tahun.

Beberapa hal yang perlu diakomodir sebagai masukan pengembangan studi selanjutnya, sebagai berikut:

1. Jumlah variasi kondisi muatan FSO agar dipertimbangkan minimal 4 (empat) variasi, yaitu kondisi muatan penuh (full load), kondisi antara-1 (intermediate-1), kondisi antara-2 (intermediate-2) dan kondisi muatan kosong (full ballast). Pada perhitungan indeks kelelahan, variasi kondisi muatan tersebut memiliki prosentase atau porsi masing-masing sesuai dengan kondisi riil operasionalnya.

2. Variasi arah datang gelombang agar dipertimbangkan lebih bervariasi sesuai dengan ketentuan klasifikasi dengan interval $30^{\circ}$.

3. Lokasi kritis yang dijadikan obyek penelitian akan lebih baik jika ditambahkan pada lokasilokasi lain agar benar-benar dapat merepresentasikan umur kelelahan dari keseluruhan konstruksi lambung FSO Arco Ardjuna.

4. Input beban yang diaplikasikan dalam analisa struktur dapat dikembangkan dengan mengakomodir gaya geser dan momen lengkung sebagai akibat dari 6 (enam) macam respon gerakan.

\section{DAFTAR PUSTAKA}

[1] Djatmiko, E.B. 2012. Fatigue Analysis on Ocean Structures. Department of Ocean Engineering Faculty of Marine Technology ITS Surabaya.

[2] Guedes Soares, C., Garbatov, Y., and von Selle, H. 2003. Fatigue Damage Assessment of Ship Structures Based On The Long-Term Distribution of Local Stresses. International Shipbuilding Program, Vol. 50, No. 1 \& 2: 35-55.

[3] Folso, Rasmus. 1998. Spectral Fatigue Damage Calculation In The Side Shells Of Ships, With Due Account Taken Of The Effect Of Alternating Wet And Dry Areas. Marine Structures, Vol. 11: 319-343.

[4] Kim, Yeong-Pyo. et al. 2002. Spectral Fatigue Analysis for Side Longitudinals and Hopper Knuckle Connection in VLCCs and FPSO. International Offshore and Polar Engineering Conference, Proceedings of The Twelfth.

[5] Xiang-chun, L., Guo-qing, F., and Hui-long, R. 2006. Study on The Application Of Spectral Fatigue Analysis. Journal of Marine Science and Application, Vol 5 (2): 42-46.

[6] Shehzad , Khurram. et al. 2013. Study on Spectral Fatigue Assessment of Trimaran Structure. Research Journal of Applied Sciences, Engineering and Technology 5(3): 10151021

[7] American Bureau Shipping. 2014. Rules for Building and Classing : Floating Production Installations. Houston. 
[8] American Bureau Shipping. 2010. Guidance Notes on Spectral-Based Fatigue Analysis for Floating Offshore Structure. Houston.

[9] Djatmiko, E.B. 1992. Hydro-Structural Studies on SWATH Type Vessel. Thesis for the Degree of Doctor of Philosophy, Scotland: Department of Naval Architecture and Ocean Engineering, University of Glasgow.

[10] Det Norske Veritas. 2014. Classification Notes No. 30.7: Fatigue Assessment of Ship Structures. Norway.

[11] Djatmiko, E.B. 2012. Perilaku Operabilitas Bangunan Laut di Atas Gelombang Acak. Surabaya: ITS Press.

[12] Biro Klasifikasi Indonesia. 2012. Fatigue Analysis Report of OSB Arco Ardjuna No. 07461/JM-227/06-12. Jakarta. 


\section{- Halaman ini sengaja dikosongkan -}

